\title{
Triquinosis: Entre el temor y el deber de informar la fuente de infección
}

\author{
CLAUDIO VALENCIA V. ${ }^{1}$, HÉCTOR MUÑOZ A. ${ }^{2}$ y MARISA TORRES H. ${ }^{3}$
}

\section{Triquinosis: between the fear and the necessity of informing the source of infection}

We present an epidemic of Trichinosis in a family group, acquired by the ingestion of brochettes. Although two patients had to be hospitalized because of the severity of symptoms of Trichinosis, other family members also presented symptoms but it was not feasible to obtain information about the source of the infection. The fear of punishment in addition to the lack of conscience of the importance of providing information of the origin of the infected meat, lead to these situations. We present this epidemic with the idea of encouraging the education on Trichinosis in the population.

Key words: Trichinosis, Infection, Education.

\section{Introducción}

La triquinosis humana en Chile es de carácter endémico. Los primeros casos autóctonos se publicaron hace cien años ${ }^{1}$. Es una zoonosis cosmopolita estrechamente relacionada a hábitos culturales y a la dieta, se transmite por carnivorismo afectando al hombre y a otros mamíferos. $\mathrm{Se}$ reconocen ciclos doméstico y silvestre. La epidemiología de triquinosis está en constante revisión, incluso a nivel mundial se ha considerado como una infección reemergente pues han aparecido especies nuevas, producto de que el hombre ha invadido otros hábitats exponiéndose así a nuevos ciclos de infección.

En el presente trabajo se presenta un brote autóctono con el objetivo de fomentar el estudio sobre triquinosis en sus aspectos fisiopatológicos, clínicos y epidemiológicos.

Existen más de ocho especies de Trichinella, con sus propios huéspedes (Tabla 1). La mayoría de los casos humanos se producen por la especie Trichinella spiralis, aunque no debe excluirse el riesgo potencial de adquirir infección por otras especies ${ }^{2-4}$.

En el ciclo doméstico tiene mucha importancia el reservorio constituido por la rata y el cerdo.
Este último se infecta generalmente al consumir ratas muertas, las que a su vez adquieren esta patología por canibalismo, al ingerir ratas infectadas. El hombre se puede infectar al consumir carne de cerdo mal cocida, que contenga larvas vivas en su musculatura 5 .

Trichinella sp desarrolla dos fases, una entérica y otra tisular. En la entérica produce cambios fisiológicos de importancia, entre ellos migración de leucocitos al tejido linfático, inducción a los

Tabla 1. Especies de Trichinella y sus reservorios naturales

\begin{tabular}{ll}
\hline Especie & Fuente de infección \\
\hline T. spiralis $\left(\mathrm{T}_{1}\right)$ & Cerdo, jabalí, oso, caballo, lobo \\
T. nativa $\left(\mathrm{T}_{2}\right)$ & Oso, caballo \\
T. britovi $\left(\mathrm{T}_{3}\right)$ & Cerdo, jabalí, caballo, perro \\
T. pseudospiralis $\left(\mathrm{T}_{4}\right)$ & Aves, mamíferos omnívoros \\
$\mathrm{T}_{5}$ & Oso \\
T. murrelli $\left(\mathrm{T}_{6}\right)$ & Oso \\
T. nelsoni $\left(\mathrm{T}_{7}\right)$ & Jabalí \\
$\mathrm{T}_{8}$ & León \\
T. papue & Cerdo \\
\hline
\end{tabular}

\footnotetext{
Estudiante de Medicina, Facultad de Medicina, Universidad de Chile.

Departamento de Epidemiología, Servicio de Salud del Libertador Bernardo O’Higgins, VI Región.

Departamento de Parasitología, Pontificia Universidad Católica de Chile.
} 
linfocitos Th2 para liberar citoquinas e interleuquinas especialmente IL-4 y producción de anticuerpos del tipo $\operatorname{IgE}$ e $\operatorname{IgG}_{1}$. En la lámina propia estimula la migración de eosinófilos y mastocitos, los que liberan mediadores proinflamatorios $^{6,7}$.

La enteropatía en el huésped podría ser el resultado de la adhesión, migración y alimentación del parásito localmente o daño secundario a infecciones bacterianas oportunistas en un tejido alterado. En modelos experimentales empleando ratones normales y transgénicos, se observa atrofia de la vellosidad intestinal, hiperplasia de las criptas, de células globosas e infiltración de eosinófilos y mastocitos en la mucosa, los que cumplirían, más que un rol protector, un rol inmunopatológico que contribuiría a mantener la inflamación local ${ }^{7}$. Esta hipótesis se basa en experimentos efectuados en ratones infectados con Trichinella sp deficientes del receptor 1 de TNF, y de la óxido nítrico sintetasa inducible; la expulsión de los parásitos en éstos ocurre con un daño tisular mínimo, en una aparente ausencia de mastocitosis intestinal respecto a los ratones controles $^{7,8}$.

En la fase muscular $T$. spiralis, produce un daño severo en las células musculares seguido por la activación y proliferación de células satélites; concomitantemente ocurre un proceso de reparación similar al producido después de un

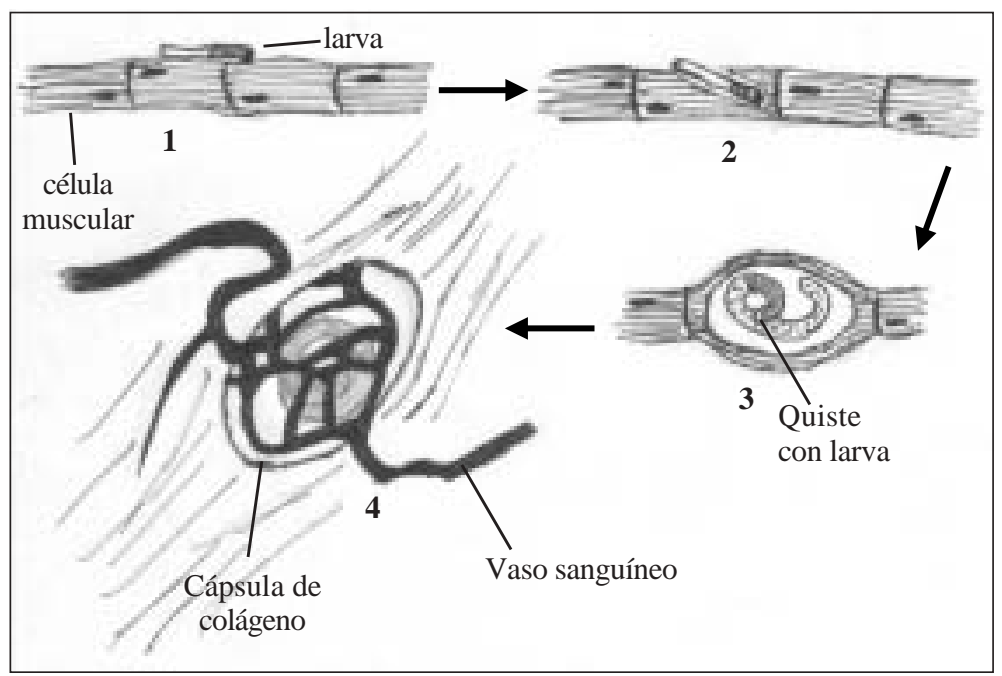

Figura 1. Ilustración del mecanismo que utiliza la larva de T. spiralis para penetrar en la célula muscular del huésped. En (1) la larva comienza a reptar sobre la célula muscular, (2) luego entra en la célula y activa programa de reestructuración del citoesqueleto, (3) una vez dentro de la célula se enrolla sobre si misma y comienza a formar un quiste y (4) en esta etapa comienza a desarrollar un programa angiogénico y se encapsula en una vaina de colágeno para su nutrición y protección. daño mecánico, con la expresión de factores regulatorios miogénicos (Myo $\mathrm{D}$, miogenina y MRF-4) ${ }^{9}$.

Las hipótesis sugieren que la larva, al entrar a la célula muscular, asume el rol de arquitecto y constructor, informando al hospedero (célula huésped), vía péptidos, cómo ir cambiando su entorno. El resultado de este proceso es la transformación de la célula muscular a una forma llamada "célula nodriza", lo que sumado a su capacidad de iniciar un programa angiogénico, le permite asegurar la adquisición de nutrientes y la eliminación de desechos por muchos años (Figura 1). Por otra parte, las células satélites que normalmente cumplen un rol de reparación tisular y pueden generar nuevas células musculares, no proliferan en esta situación a células musculares sino que a células nodrizas, produciéndose una fusión con éstas. Finalmente este nuevo tipo celular se rodea por una cápsula de colágeno de dos tipos, IV y VI ${ }^{9,10}$.

\section{Casos clínicos}

Se describe un brote epidémico de 5 personas (2 pacientes hospitalizados y 3 ambulatorios). Todos correspondían a un grupo familiar que ingirió carne de cerdo infectada en forma de "anticuchos" (pequeños trozos de carne asada) durante el mes de abril del año 2001, en la ciudad de Rancagua. Según el estudio epidemiológico, la fuente infectante fue adquirida a un comerciante ilegal de la comuna de Doñihue.

El caso índice fue una paciente de 28 años, que consultó a un servicio asistencial 10 días antes de ser internada, recibiendo prescripción de analgésicos y antiinflamatorios. Volvió a consultar constatándose la presencia de eosinofilia en su hemograma 1.755 eosinófilos $/ \mathrm{mm}^{3}$ (18\% de 9.750 leucocitos), síndrome febril $\left(\mathrm{T}^{\circ} 39^{\circ} \mathrm{C}\right.$ ), acompañado por intensas mialgias y síndrome edematoso facial (Tabla 2). Fue internada en el Hospital Regional con el diagnóstico presuntivo de triquinosis.

Entre sus antecedentes epidemiológicos, destacaba 
Tabla 2. Recuento diferencial de leucocitos en paciente 1

\begin{tabular}{lccccccccc}
\hline $\begin{array}{c}\text { Leucocitos/ } \\
\mathrm{mm}^{3}\end{array}$ & $\begin{array}{c}\text { Basofilos } \\
(\%)\end{array}$ & $\begin{array}{c}\text { Eosinófilo } \\
(\%)\end{array}$ & $\begin{array}{c}\text { Mielocitos } \\
(\%)\end{array}$ & $\begin{array}{c}\text { Juveniles } \\
(\%)\end{array}$ & $\begin{array}{c}\text { Baciliformes Segmentados Linfocitos } \\
(\%)\end{array}$ & $\begin{array}{c}\text { Monocitos } \\
(\%)\end{array}$ \\
\hline Etapa ambulatoria & 9.750 & 0 & 18 & 0 & 0 & 3 & 56 & 22 & 1 \\
Hospitalización & 8.300 & 0 & 2 & 0 & 0 & 0 & 68 & 28 & 2 \\
\hline
\end{tabular}

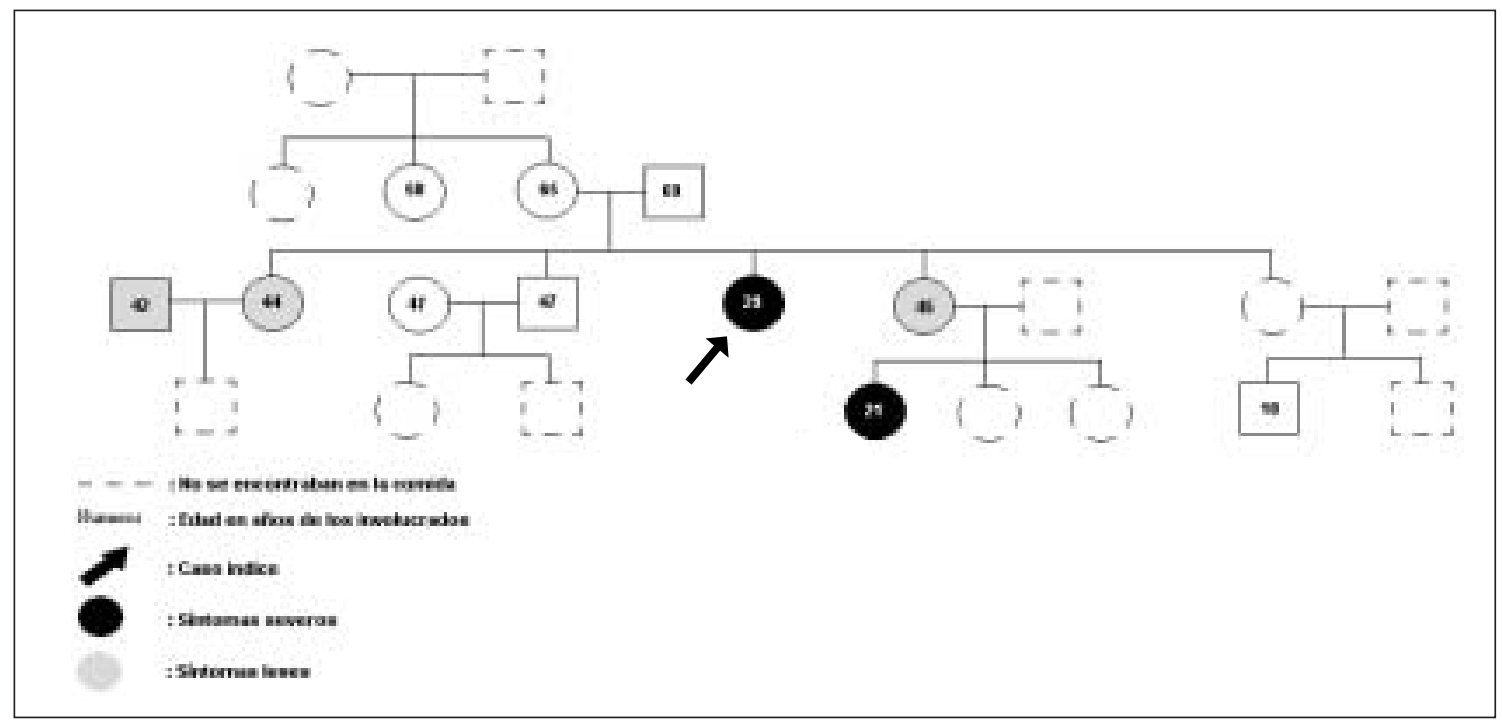

Figura 2. Árbol genealógico del grupo familiar involucrado.

que 20 días antes del ingreso había ingerido carne de cerdo en forma de anticuchos, en una reunión familiar donde participaran otras 10 personas (Figura 2).

Entre sus exámenes destacaban creatinfosfoquinasa (CPK) total de $325 \mathrm{U} / \mathrm{L}$ (normal 24$170 \mathrm{U} / \mathrm{l})$ y PCR de $1,42 \mathrm{mg} / \mathrm{dl}$, IgG para triquinosis negativa (test de ELISA). Se le indicó medidas generales: reposo absoluto, hidratación, tratamiento antiparasitario específico con albendazol $200 \mathrm{mg}$ cada 12 horas oral durante 14 días; tratamiento sintomático con ranitidina $150 \mathrm{mg}$ cada 8 horas intravenosa, hidrocortisona $100 \mathrm{mg}$ cada 8 horas intravenosa y diclofenaco sódico 75 mg cada 8 horas intramuscular. La paciente evolucionó satisfactoriamente, con disminución de mialgias y mejoría importante de su estado gene- ral. Se le dio de alta al cuarto día de hospitalización, en buenas condiciones generales.

El segundo caso, fue una paciente de 21 años sobrina del caso índice. Esta paciente presentaba compromiso del estado general por lo que consultó en un servicio de emergencia presentando un cuadro clínico similar al anterior. En ella destacaba un síndrome febril con $\mathrm{T}^{\circ}$ axilar de $39,5^{\circ} \mathrm{C}$; y entre sus exámenes de laboratorio, leucocitosis de $17.200 / \mathrm{mm}^{3}$ (eosinofilia $45 \%$ ), fosfatasa alcalinas totales $295 \mathrm{U} / \mathrm{L}(\mathrm{n}=0-240) \mathrm{y}$ CPK 686 U/L (Tabla 3).

Ambas pacientes evolucionaron satisfactoriamente con terapia sintomática (analgesia y antiinflamatorios), y terapia antiparasitaria. El estudio serológico (ELISA) para triquinosis IgG, IgA e IgM resultó positivo a los 21 días para el

Tabla 3. Recuento diferencial de leucocitos en paciente 2

\begin{tabular}{cccccccc}
\hline $\begin{array}{c}\text { Basofilos } \\
(\%)\end{array}$ & $\begin{array}{c}\text { Eosinófilos } \\
(\%)\end{array}$ & $\begin{array}{c}\text { Mielocitos } \\
(\%)\end{array}$ & $\begin{array}{c}\text { Juveniles } \\
(\%)\end{array}$ & $\begin{array}{c}\text { Baciliformes } \\
(\%)\end{array}$ & $\begin{array}{c}\text { Segmentados } \\
(\%)\end{array}$ & $\begin{array}{c}\text { Linfocitos } \\
(\%)\end{array}$ & $\begin{array}{c}\text { Monocitos } \\
(\%)\end{array}$ \\
\hline 0 & 45 & 0 & 0 & 1 & 33 & 20 & 1 \\
\hline
\end{tabular}


segundo caso descrito. El resto de los integrantes del grupo familiar presentaron sintomatología leve y se trataron ambulatoriamente en forma sintomática.

De la investigación epidemiológica sobre la fuente infectante, se constató que el cerdo fue adquirido en el sector Punta de Cortes (comuna de Doñihue, zona rural) y se habría repartido entre cuatro grupos familiares, en el mismo sector. El cerdo había sido consumido en forma de "anticuchos" el 28 de abril por el grupo familiar en estudio, ingiriendo de él 11 personas, el resto de la carne se consumió como "cazuela". Debido a presiones externas y temor de recibir alguna sanción por entregar información a las autoridades sanitarias, ninguno de los involucrados entregó información y no se logró identificar la procedencia de la fuente infectante.

\section{Comentario}

La triquinosis es una zoonosis presente en Chile y otros países de Latinoamérica. La mayoría de las veces se presenta como un brote afectando generalmente a personas que ingieren una fuente infectante común.

En Chile, en el periodo comprendido entre 1989 y 1998 se notificaron 675 casos de triquinosis. El 91,3\% se produjo entre la Región Metropolitana y la X Región, siendo el segmento comprendido entre la VIII y X Región el más afectado $(68,9 \%$ de los casos del total nacional) ${ }^{11}$.

En la distribución por sexo, no hubo diferencias significativas $(50,5 \%$ varones y $49,5 \% \mathrm{mu}-$ jeres), el rango etario con mayor incidencia fue el comprendido entre 15 y 44 años $(64,1 \%$ de los (asos) $)^{11}$.

Los estudios han mostrado, que con el mejoramiento de las condiciones sanitarias del país, la incidencia de triquinosis ha disminuido de 1,4/ 100.000 habitantes entre 1961-1971 a 0,3/100.000 en 1998. Aún así, la prevalencia de la infección en el reservorio humano, observada a través de estudios de autopsias del Servicio Médico Legal (la cual cubre un $40 \%$ por ciento de la población chilena) en muestras de diafragma de personas aparentemente sanas, alcanzó a 2\% en 1992 y $0,8 \%$ en 1997. Además censos serológicos ( $\operatorname{IgG})$ para triquinosis realizados en 13.000 personas elegidas al azar de todo el país, demostraron una positividad del $1,5 \%$, lo que evidencia reconocimiento antigénico al parásito y presencia de riesgo de infección a lo largo del país ${ }^{11}$.

En Chile, se reconocen zonas endémicas con ciclos en la aparición de brotes epidémicos, los que aumentan entre abril y septiembre porque se produce el mayor consumo de carne de cerdo. Durante esta época se faena mayor cantidad de cerdos criados en domicilios sin inspección sanitaria. Este factor, asociado a la crianza de animales en malas condiciones higiénicas y a la falta de información de la población sobre la forma de consumo de la carne, acrecienta el riesgo de contraer la infección, principalmente en familias de escasos recursos y de nivel educacional deficiente.

El diagnóstico de triquinosis depende de la sospecha clínica, identificación y correlación de los signos y síntomas clínicos, además de los hallazgos positivos del laboratorio (eosinofilia y CPK aumentada). Esta enfermedad generalmente es mal diagnosticada, porque sus signos y síntomas se confunden en el comienzo del cuadro con intoxicación alimentaria o gastroenteritis, cuadros de gripe y enfermedades autoinmunes. A esto se suma la creencia de muchos médicos clínicos de que la seroconversión de los anticuerpos contra Trichinella sp ocurre tempranamente en los pacientes, lo que no sucede en la mayoría de los casos, ya que la elevación de los anticuerpos se debe fundamentalmente al incremento de compuestos antigénicos liberados por larvas ya dañadas durante la fase de migración o incluso, después de la terapia antiparasitaria. En la práctica clínica es recomendable tratar a pacientes con cuadro clínico sospechoso, antecedentes epidemiológicos de riesgo y presencia de eosinofilia y aumento de CPK, y no esperar la detección de anticuerpos circulantes para certificar el diagnóstico ${ }^{3,12,13}$.

La eosinofilia es el hallazgo e indicador de laboratorio más temprano y característico de la triquinosis (que en casos asintomáticos puede variar entre 5 y $15 \%$ del recuento total de leucocitos).

En este brote cabe destacar que la fuente infectante fue una forma de preparación poco habitual del cerdo (anticucho) ya que en Chile, los anticuchos se preparan generalmente con carne de bovino.

Se constata la falta de sospecha diagnóstica frente al cuadro clínico sugerente por parte de profesionales de la salud.

Como ya es tradicional entre los infectados se observan diversos grados de manifestaciones clínicas de la infección dependiendo del número de larvas ingeridas.

En relación, a la expresión hematológica observada en la primera paciente en la cual se observó un descenso de los eosinófilos en la 
sangre de 18 a $2 \%$ sin mediar terapia antiparasitaria, debe recordarse que el incremento de eosinófilos en sangre es un proceso dinámico y variable en el tiempo; la vida media intravascular del eosinófilo es de 3 a 8 horas, ya que después migra hacia los tejidos ${ }^{14}$.

Ante un presunto brote de triquinosis es fundamental la notificación precoz a las autoridades competentes en los servicios de salud, aun frente a la mera sospecha clínica; es muy importante identificar y decomisar la fuente de infección, identificar nuevos casos y adoptar medidas epidemiológicas adecuadas para controlar el brote epidémico. Es importante señalar que las autoridades sanitarias tienen en Chile una red de vigilancia epidemiológica activa que actúa frente a la sospecha de un caso índice notificado.

Ya que los indicadores globales de salud en Chile han mejorado en estos últimos años (mortalidad, expectativa de vida, etc), existe la falsa creencia de que patologías zoonóticas parasitarias han disminuido o no están presentes, esto ha llevado a disminuir la educación a la comunidad. Al no educar no se produce la toma de conciencia de la comunidad en este tema obstaculizando las intervenciones para cortar el ciclo de transmisión al hombre, lo que en este caso se vio expresado en la falta de compromiso para entregar la información sobre la fuente infectante ${ }^{11,15,16}$. La autoridad sanitaria no realiza acciones punitivas en esta área, sino que protege personas potencialmente expuestas al riesgo de infección.

\section{Resumen}

Se presenta un brote de triquinosis en un grupo familiar adquirido por la ingestión de "anticuchos". Aunque dos pacientes debieron ser hospitalizados por la gravedad del cuadro de triquinosis y otros miembros de la familia también presentaron sintomatología, no fue posible obtener información sobre la fuente infectante. El temor a recibir alguna sanción, sumado a la falta de conciencia de la importancia de entregar información sobre el origen de la carne infectada, genera estas situaciones. Se presenta el brote con el objetivo de fomentar la educación sobre triquinosis en la población.

\section{Bibliografía}

1.- Schenone H, López R, Barilari E., Contreras M., Castillo D. Tendencia actual de la Epidemiología de la Triquinosis Humana en Chile. Bol Chil Parasitol 1997; 52: 22-5.

2.- Wakelin D. Immunology and Genetics of Zoonotics Infection Involving Parasites. Comp Immunol Microbiol Infect Dis 1996; 19: 256-65.

3.- Capo V, Despoimmier D D. Clinical aspects of infection with Trichinella spp Clin Microbiol Rev 1996; 9: 47 54.

4.- Morgan U M. Detection and characterization of parasites causing emerging zoonosis. Int. J Parasitol 2000; 30: 1407-21.

5.- Atias A. Triquinosis. En: Atías A. Parasitología Médica. Santiago. Editorial Mediterráneo 1998: 318-24.

6.- McDermott J, Grencis R, Else K. Leukocyte recruitment during enteric nematode infection. Immunology 2001; 103: 505-10.

7.- Gardise P, Kennedy M, Wakelin D, Lawrence C. Immunopathology of intestinal helminth infection. Parasite Immunol 2000; 22: 605-12.

8.- Lawrence C E, Paterson JC, Wei X Q, Liew F Y, Garside P, Kennedy M W. Nitric oxide mediates intestinal pathology but not immune expulsion during Trichinella spiralis infection in mice. J Immunol 2000; 164 (8): 4229-34.

9.- Wu Z, Nakada T, Takahashi Y. Different response of satellite cell in the kinetics of miogenic regulatory factors and ultraestructural pathology after Trichinella spiralis y Trichinella speudospiralis infection. Parasitology 2001; 123: 85-94.

10.- Despommier D D. How does Trichinella spiralis make itself at home. Parasitol Today 1998, 14: 318-23.

11.- Schenone H, Olea A, Schenone H (Jr), Contreras M, Mercado R, Sandoval L. Present epidemiological situation of trichinellosis in Chile (1989-1998). Abstract $X^{\text {th }}$ International Conference of Trichinellosis. Fontaineblau, France. 20-24 August 2000. Abstract 116SU.11

12.- Wang Z Q, Cui J, Wu F, Mao F R, Jin X X. Epidemiological, clinical and serological studies on Trichinellosis in Henan Province, China. Acta Tropica 1998; 71: 255-68.

13.- Baar A, Torres M, Rabagliati B. Triquinosis: Importancia del caso índice. Rev Chil Infect 1999; 3: 225 31.

14.- Rothenberg M. Eosinophilia. N Engl J Med 1998; 22: 1592-600.

15.- Murrel K D, Pozio E. Trichinellosis: the zoonosis that won't go quietly. Int J Parasitol 2000; 30: 133949.

16.- International Comission on Trichinellosis. Data compiled from What to do in case of an outbreak? www.med.unipi.it/ict/outbr1.htm.Accedido. accedida en marzo 2003.

Correspondencia a:

Claudio A. Valencia Valencia

E-mail: cavalenc@yahoo.com o cavalenc@puc.cl 